\title{
PELATIHAN PROGRAM PENGEMBANGAN KEPROFESIAN BERKELANJUTAN (PKB) UNTUK GURU SEKOLAH DASAR DI LINGKUNGAN DINAS PENDIDIKAN DAN KEBUDAYAAN KOTA SUKABUMI
}

\author{
Dyah Lyesmaya ${ }^{1(a)}$, Fanny Sumirat ${ }^{2}$, Deden Sumiarsa ${ }^{3}$, \\ lis Nurasi'ah ${ }^{1}$, Rohmat Widiyanto ${ }^{1}$, Din Azwar Uswatun ${ }^{1}$, Arif Yudiyanto ${ }^{1}$, \\ Zaenudin Aang ${ }^{4}$
}

\begin{abstract}
Becoming a teachers means always encourage yourself for longlife education. This is one of the benefit in Teacher career. We used to be learn anything and everything to update our professionalism. As a Teacher, we should be aware of teachers world, knowledge, technology, and student needs changing. Indonesian Government facilitate it through PKB (Continuity Profesionalism Development) program. PKB goals is to increasing teachers career competence continualy. Although Government publish this program since 2009, Education and Culture Departement of Sukabumi City started it in 2015 October. This lateness becoming our concern to organize a PKB Workshop specialy for elemetary school teachers. This workshop attendence by fifty teachers from seven distrik in Sukabumi city. The Workshop goals is to diseminate PKB and how to running it in teachers career. Beside that, the workshop also trained teacher how to entablish class action reasearch. This workshop held in three days from 2nd to 4th November 2016. From the workshop we know that PKB is very important to increase teachers competence and to maintain teachers career.
\end{abstract}

Keywords: Elementary School Teachers, PKB Workshop, Teachers Profesionalism.

JURNAL PENGABDIAN PADA MASYARAKAT

Website: http://ojs.ejournal.id/index.php/ppm

Permalink: http://ojs.ejournal.id/index.php/ppm/article/view/83

How to cite (APA): Lyesmaya, D., et al. (2017). Pelatihan program pengembangan keprofesian berkelanjutan (PKB) untuk guru sekolah dasar di lingkungan dinas pendidikan dan kebudayaan Kota Sukabumi. Jurnal Pengabdian Pada Masyarakat, 2(1), 41-50.

This is an open access article distributed under the terms of the Creative Commons Attribution 4.0 International License, which permits unrestricted use, distribution, and reproduction in any medium, provided the original work is properly cited.

\section{PENDAHULUAN}

Pemerintah terus menerus mengupayakan peningkatan kualitas Sumber Daya Manusia melalui kompetensi guru di Indonesia. Salah satu program

\footnotetext{
${ }^{1}$ Universitas Muhammadiyah Sukabumi; Jalan.R. Syamsudin, SH. No. 50.

${ }^{2}$ Universitas Islam ‘45 Bekasi.

${ }^{3}$ SDN Cibungur Kota Sukabumi.

${ }^{4}$ Dinas Pendidikan dan Kebudayaan Kota Sukabumi.

a email: lyesmaya_dyah@ummi.ac.id
} 
pemerintah adalah dengan menyelenggarakan program Pengembangan Keprofesian Berkelanjutan (PKB). Program PKB adalah upaya dalam meningkatkan profesionalisme guru agar memiliki kompetensi sesuai dengan peraturan perundang-undangan serta perkembangan ilmu pengetahuan, teknologi, dan atau/seni. Program PKB ini diatur melalui Permenag PAN dan RB Nomor 16 Tahun 2009 pasal 11 ayat c. Permenag tersebut berbunyi bahwa komponen Pengembangan Keprofesian Berkelanjutan terdiri dari tiga hal yaitu; Pengembangan Diri (terdiri dari diklat fungsional dan kegiatan kolektif guru), Publikasi IImiah (presentasi pada forum ilmiah, Publikasi ilmiah atas hasil penelitian atau gagasan ilmu di bidang pendidikan formal, dan publikasi buku pelajaran, buku pengayaan, dan pedoman guru), dan Karya Inovatif (menemukan teknologi tepat guna, menemukan/menciptakan karya seni, membuat/memodifikasi alat pelajaran/peraga/praktikum, dan mengikuti pengembangan penyusunan standar, pedoman, soal dan sejenisnya). Adapun tingkatan jenjang karir guru berdasarkan PKB terlihat pada Gambar 1.

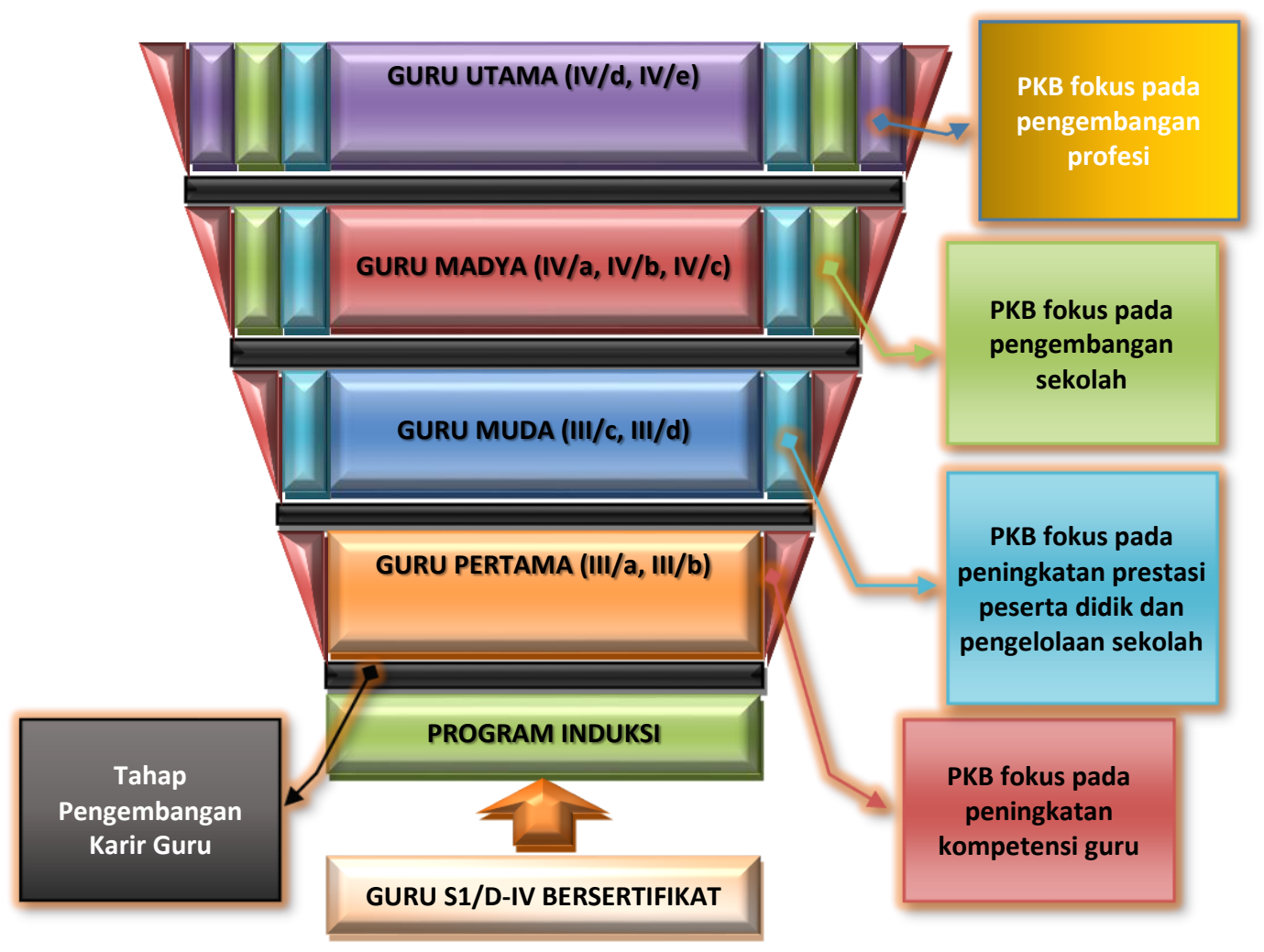

Gambar 1. Jenjang Karir Guru 
Sejatinya program ini dilaksanakan diseluruh indonesia sejak 2009 atau sejak 2012. Namun di Sukabumi, baru berjalan pada Oktober 2015. Kenaikan pangkat melalui program PKB, sudah dilaksanakan dalam tiga termin, yaitu Oktober 2015, April 2016, dan Oktober 2016. Berdasarkan hasil wawancara dengan Kadis Kota Sukabumi, keterlambatan ini terjadi karena lambatnya sosialisasi dari pusat dan kurangnya informasi terkait PKB ke sekolah. Oleh sebab itu, kami, yang terdiri dari lima orang dosen UMMI, satu orang dosen UNISMA, Kasubag.Kepegawaian Dinas P\&K Kota Sukabumi, dan satu orang guru SDN Cibungur Kota Sukabumi berinisiatif mengadakan pelatihan program PKB sebagai upaya membangun kesadaran profesionalisme guru terutama untuk guru SD di lingkungan Dinas Pendidikan dan Kebudayaan Kota Sukabumi.

Pada observasi awal, kami memperoleh data bahwa jumlah guru SD di lingkungan Dinas P\&K Kota Sukabumi berjumlah 1064 orang yang tersebar pada tujuh UPT kecamatan yaitu; Cikole, Lembur Situ, Citamiang, Warudoyong, Baros, Gunung Puyuh, dan Cibeureum. Berdasar data dari BKD Sukabumi, guru SD yang mengajukan pangkat sejak Oktober 2015 adalah 115 orang atau $11 \%$ dari jumlah keseluruhan. Untuk itu, kami mengundang perwakilan sekolah untuk mengikuti kegiatan pelatihan program PKB yang terdiri dari satu orang pengawas untuk setiap kecamatan, satu orang guru SD yang mengikuti program PKB, dan empat orang guru yang belum mengikuti PKB. Namun pada saat pelaksanaan ada beberapa guru yang ikut serta sehingga jumlah peserta menjadi 50 orang.

\section{METODE PELAKSANAAN}

Khalayak sasaran utama dari kegiatan ini adalah guru Sekolah Dasar perwakilan dari setiap SD, dan pengawas dari perwakilan setiap UPT . Dari undangan yang disebar ke seluruh SD dan UPT di Kota Sukabumi, yang menghadiri kegitan adalah sepuluh pengawas dan empat puluh orang guru. Semua peserta dalam kegiatan pengabdian ini adalah pengawas dan guru yang belum dan sedang menyusun fortopolio untuk kenaikan pangkat berdasarkan program PKB. Pada umumnya, peserta kesulitan menyusun portofolio terutama mengenai persyaratan PTK (Penelitian Tindakan Kelas) yang menjadi syarat kenaikan pangkat.

Untuk membantu mengatasi permasalahan yang dihadapi peserta dipilih beberapa metode pendekatan, yaitu: 1) Kegiatan sosialisasi, pemaparan dasar hukum dan kegiatan-kegiatan yang terdapat dalam program PKB 
yang dilakukan di Aula Dinas Pendidikan dan Kebudayaan Kota Sukabumi; 2) Pelatihan dan pendampingan, pemaparan teori melalui metode diskusi mengenai pengembangan diri, publikasi ilmiah, dan karya inovatif; 3) Refleksi, tindak lanjut hasil sosialisasi dan pelatihan.

Adapun pelaksanaan kegiatan dilakukan dalam beberapa tahapan sebagai berikut.

\section{Tahap Persiapan}

Pada tahap persiapan terdiri dari dua kegiatan, yaitu observasi awal dan perencanaan kegiatan. Tahapan observasi awal dilakukan untuk mengetahui bagaimana program PKB digulirkan selama ini di lingkungan Dinas P\&K Kota Sukabumi. Observasi awal dilakukan melalui wawancara dengan kepala dinas, sekretaris, kasubag.kepegawaian, dan Kabid.Pendas melalui Kasi Manajemen dan Kurikulum di lingkungan dinas P\&K kota Sukabumi. data yang diperoleh melalui observasi awal ini, kemudian ditindak lanjuti dengan membuat perencanaan sosialisasi, pelatihan dan pendampingan PKB.

\section{Tahap Sosialisasi}

Tahapan sosialisasi merupakan tahapan pemaparan mengenai dasar hukum dan kegiatan-kegiatan yang terdapat dalam program PKB. Pemaparan yang dimaksud diantaranya adalah pemaparan mengenai macam dan kegiatan PKB yang terlihat pada tabel berikut ini.

Tabel 1. Program Kegiatan PKB

\begin{tabular}{|c|c|c|}
\hline No & Macam PKB & Jenis Kegiatan \\
\hline 1 & $\begin{array}{l}\text { Pengembangan } \\
\text { Diri }\end{array}$ & $\begin{array}{l}\text { a) Diklat fungsional } \\
\text { b) Kegiatan kolektif guru }\end{array}$ \\
\hline 2 & Publikasi IImiah & $\begin{array}{l}\text { a) Presentasi pada forum ilmiah } \\
\text { b) Publikasi ilmiah atas hasil penelitian atau } \\
\text { gagasan ilmu di bidang pendidikan formal } \\
\text { c) Publikasi buku pelajaran, buku pengayaan, } \\
\text { dan pedoman guru }\end{array}$ \\
\hline 3 & Karya Inovatif & $\begin{array}{l}\text { a) Menemukan teknologi tepat guna } \\
\text { b) Menemukan/menciptakan karya seni } \\
\text { c) Membuat/memodifikasi alat } \\
\text { pelajaran/peraga/praktikum } \\
\text { d) Mengikuti pengembangan penyusunan } \\
\text { standar, pedoman, soal dan sejenisnya }\end{array}$ \\
\hline
\end{tabular}




\section{Tahap Pelatihan}

Tahapan Pelatihan adalah tahapan yang dilakukan setelah perencanaan dan sosialisasi dilakukan. Tahapan Pelatihan ini disesuaikan dengan hasil diskusi di tahapan sosialisasi. Pelatihan yang dilakukan adalah pelatihan yang diinginkan oleh guru berdasarkan hasil sosialisasi PKB.

\section{Tahap Refleksi}

Pada tahapan ini dilakukan urun rembuk/diskusi dan feed back atau tindak lanjut dari tahapan pelatihan dan pendampingan yang dilakukan. Dalam tahapan refleksi ini di uraikan kesulitan dan solusi yang diperoleh untuk menghadapi kesulitan dan hambatan tersebut.

\section{HASIL DAN PEMBAHASAN}

\section{Tahap Persiapan}

Pada tahap persiapan terdiri dari dua kegiatan, yaitu observasi awal dan perencanaan kegiatan. Pada observasi awal, kami memperoleh data bahwa jumlah guru SD di lingkungan Dinas P\&K Kota Sukabumi berjumlah 1064 orang yang tersebar pada tujuh UPT kecamatan yaitu; Cikole, Lembur Situ, Citamiang, Warudoyong, Baros, Gunung Puyuh, dan Cibeureum. Dinas P\&K Kota Sukabumi baru menerapka program PKB ini dalam 2 periode, yaitu pada Oktober 2015 dan April 2016. Selain itu, Berdasar data dari BKD Sukabumi, guru SD yang mengajukan pangkat sejak Oktober 2015 adalah 115 orang atau 11\% dari jumlah keseluruhan. Hal ini terjadi karena kurangnya sosialisasi yang dilakukan. Untuk itu, kami melakukan perencanaan untuk mengadakan kegiatan sosialisasi mengenai macam dan kegiatan program PKB dan bagaimana melaksanakannya.

Berdasarkan hasil perencanaan, kami menyusun materi sosialisasi dan merencanakan kegiatan dengan melakukan koordisasi dengan kasubag.kepegawaian untuk mengundang perwakilan sekolah untuk mengikuti kegiatan pelatihan program PKB. Peserta yang kami undang yang terdiri dari satu orang pengawas untuk setiap kecamatan, satu orang guru SD yang mengikuti program PKB, dan empat orang guru yang belum mengikuti PKB. Namun pada saat pelaksanaan ada beberapa guru yang ikut serta sehingga jumlah peserta menjadi 50 orang. 


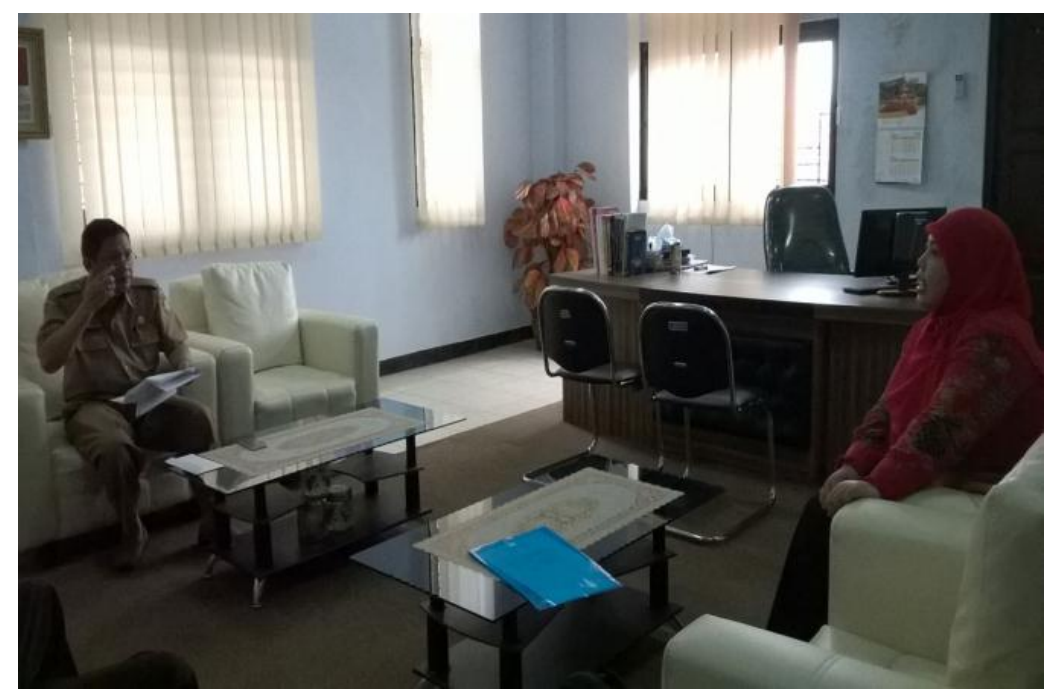

Gambar 2. Wawancara dengan Kepala Dinas P\&K Kota Sukabumi

\section{Tahap Sosialisasi}

Tahapan sosialisasi merupakan tahapan pemaparan mengenai dasar hukum dan kegiatan-kegiatan yang terdapat dalam program PKB. Pemaparan yang dimaksud adalah pemaparan mengenai macam dan kegiatan PKB. Kami menginformasikan bahwa program PKB ini terdiri dari tiga topik yaitu pengembangan diri, publikasi ilmiah, dan karya inovatif. Ketiga topik ini bisa dilakukan dengan cara diklat fungsional, kegiatan kolektif guru, menghadiri forum ilmiah, publikasi ilmiah, publikasi buku, menemikan teknologi, karya seni, pengembangan alat, bahan, pedoman, modul dan lain sebagainya.

Dari sosialisasi ditemukan bahwa pengembangan diri sudah dilakukan oleh guru dan sudah terprogram secara baik dari tingkat sekolah hingga tingkat dinas. Sebagian besar guru sudah memahami ini. Bahkan disebagian sekolah ada yang mengadakan in-house training setiap empat bulan sekali. Sayangnya, untuk topik karya inovatif, belum ada guru SD di kota Sukabumi yang berhasi membuat karya.

Sedangkan untuk topik publikasi ilmiah, hasil diskusi sosialisasi ini, merekomendasikan untuk mengadakan pelatihan dan pendampingan pembuatan Karya Ilmiah yaitu mengenai pembuatan bahan presentasi, pembuatan buku, dan pembuatan jurnal ilmiah. Namun sebelum kepada pendampingan pembuatan karya ilmiah ini, kami menggali informasi, ternyata sebagian besar guru tidak tahu mengenai salah satu syarat publikasi ilmiah adalah ada nya penelitian yang mendasarinya. Selain itu, 
ketika diberikan pertanyaan mengenai PTK, guru mengalami kesulitan dalam pembuatannya, sehingga, peserta dan fasilitator menyimpulkan bahwa perlu diadakannya pelatihan dan pendampingan untuk pembuatan PTK. Selain itu juga, PTK dalam PKB adalah salah satu syarat dalam kenaikan pangkat guru.

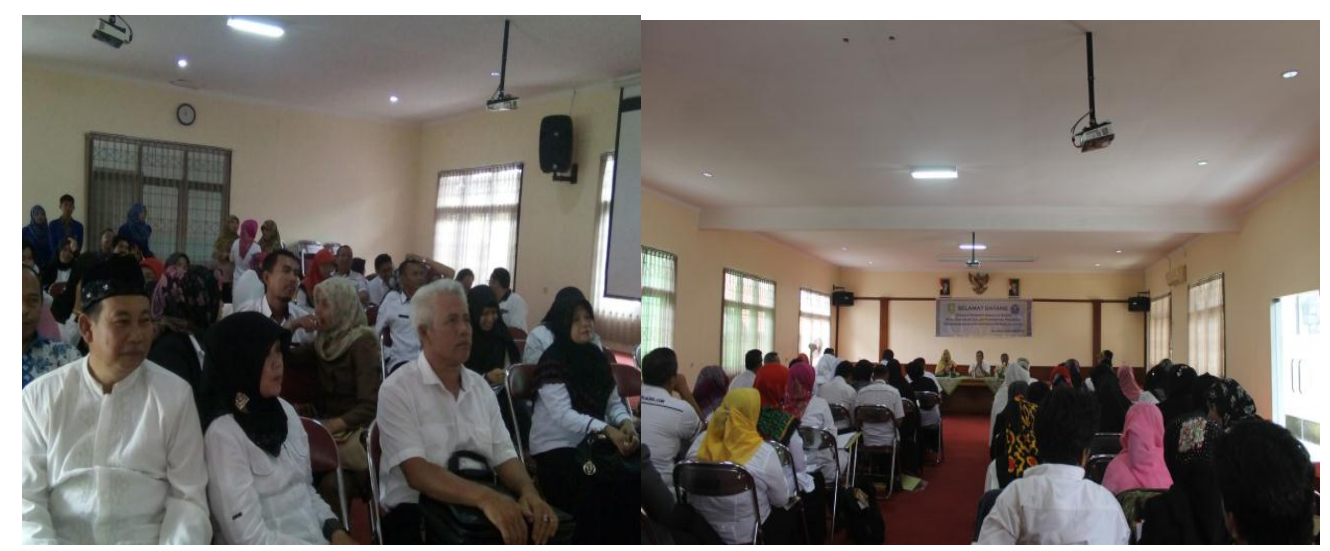

Gambar 3. Sosialisasi PKB dengan Guru SD

\section{Tahap Pelatihan}

Tahapan Pelatihan adalah tahapan yang dilakukan setelah perencanaan dan sosialisasi dilakukan. Tahapan Pelatihan yang telah disesuaikan dengan hasil diskusi di tahapan sosialisasi yaitu pelatihan mengenai Penelitian Tindakan Kelas (PTK). Pelatihan PTK dilakukan setelah sosialisasi PKB selesai di ruang Aula Dinas Pendidikan dan Kebudayaan (P\&K) Kota Sukabumi. Pelatihan dilakukan dengan cara memaparkan bagaimana PTK yang baik dan peserta menelaah contoh-contoh PTK yang diberikan fasilitator.

Hasil pelatihan memperoleh data bahwa semua guru pernah membuat PTK dan kesulitan dalam membuatnya. Sebagian besar kesulitan tersebut adalah mengenai metodologi yang dipergunakan dan fokus PTK yang diajukan untuk kenaikan pangkat yang tidak mereka pahami. Dalam hal sistematika penulisan PTK pun masih ditemukan ketidak seragaman berdasar pada standar PTK yang ada. Karenanya kami mengambil kesimpulan bahwa pembuatan PTK yang dilakukan oleh guru selama ini sebagian besar adalah asal jadi. Untuk itu kami memberikan pelatihan mengenai sistematika pembuatan PTK. Sistematika yang dijadikan materi 
Pelatihan adalah mengenai Outline, Abstrak, Metodologi Penelitian, penulisan pustaka, dan pengutipan.

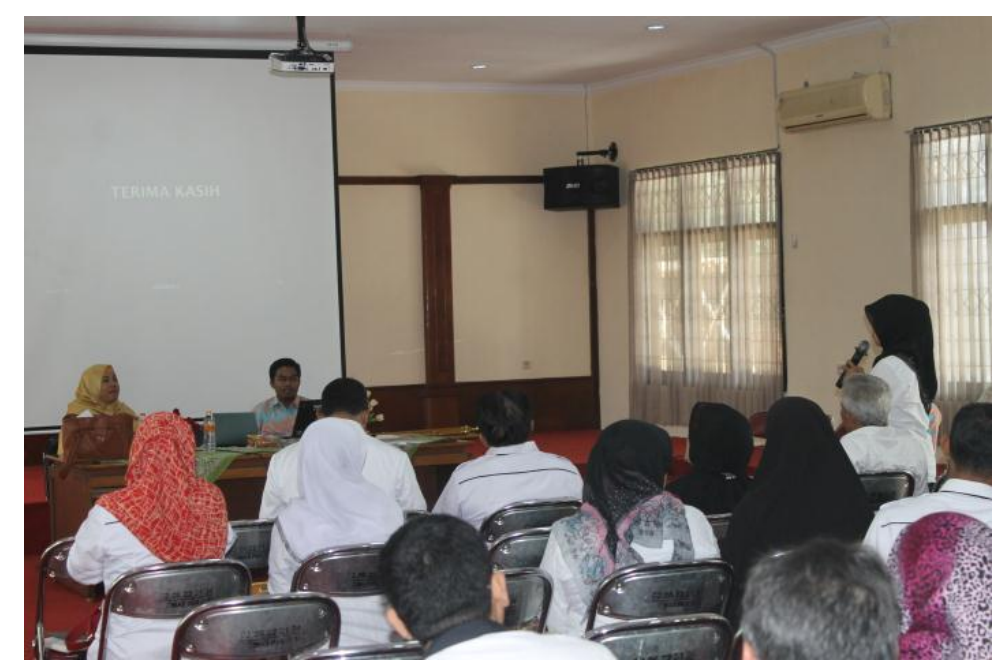

Gambar 3. Pelatihan PTK dengan Guru SD

\section{Tahap Refleksi}

Pada tahapan Refleksi, urun rembuk/diskusi dan feed back atau tindak lanjut dari tahapan pelatihan dan pendampingan, dilakukan di tujuh tempat di UPT kota Sukabumi dengan merefleksi program PKB dan Sistematika PTK. Dari hasil refleksi diperoleh hasil bahwa kegiatan PKB sangat berguna untuk meningkatkan profesionalisme guru. Namun kegiatan yang terdapat dalam PKB membutuhkan waktu dan pendampingan dari pihak dinas P\&K terutama mengenai pendampingan dan pelatihan PTK. Sebab dari hasil refleksi ternyata guru mengalami kesulitan dalam proses PTK dan perlu adanya lesson studi dengan pendampingan nara sumber mengeni perencanaan dan publikasi PTK.

\section{SIMPULAN}

Memperhatikan pelaksanaan dari setiap tahapan, maka secara umum beberapa permasalahan yang dihadapai guru dalam program PKB di kota sukabumi telah memperoleh solusi. Termasuk kurangnya informasi mengenai kegiatan yang harus diikuti dan yang harus dilakukan dalam program PKB, kesulitan dalam pembuatan karya tulis ilmiah terutama PTK, dan minimnya kesempatan untuk mengikuti pelatihan. Kegiatan 
pengabdian ini dapat pula dikatakan sebagai workshop, dimana guru-guru saling berdiskusi mengenai PKB dan PTK dengan difasilitasi tim pengabdian.

Waktu tiga hari dalam sosialisasi dirasakan cukup untuk membangun pemahaman guru mengenai program PKB, namun sangat kurang untuk pelatihan karya tulis ilmiah. Guru masih merasa kesulitan dalam menulis. Untuk itu, sebagai saran, perlu dilakukan pendampingan berkelanjutan dalam melakukan proses pembuatan PTK, termasuk di dalamnya pendampingan dalam melakukan PTK di sekolah. Selain itu, sangat penting pula dilakukan pelatihan menganai isu originalitas dan plagiarisme sebagai tindak lanjut dari penulisan karya ilmiah.

\section{REFERENSI}

Arikunto. S. (2010). Penelitian tindakan kelas. Jakarta: Rineka Cipta.

Kemendiknas. (2010). Pedoman pengelolaan pengembangan keprofesian berkelanjutan (PKB) (Buku 1). Jakarta: Pusat Pengembangan Profesi Pendidik Badan Pengembangan Sumber Daya Manusia Pendidikan dan Penjaminan Mutu Pendidikan Kemendiknas.

Kemendiknas. (2011). Peraturan menteri negara pendayagunaan aparatur negara dan reformasi birokrasi nomor 16 tahun 2009 tentang jabatan fungsional guru dan angka kreditnya. Jakarta: Pusat Pengembangan Profesi Pendidik Badan Pengembangan Sumber Daya Manusia Pendidikan dan Penjaminan Mutu Pendidikan Kemendiknas.

Kemendiknas. (2011). Pedoman pengelolaan pengembangan keprofesian berkelanjutan (PKB) (Buku 4). Jakarta: Pusat Pengembangan Profesi Pendidik Badan Pengembangan Sumber Daya Manusia Pendidikan dan Penjaminan Mutu Pendidikan Kemendiknas.

Kemendiknas. (2011). Pedoman pengelolaan pengembangan keprofesian berkelanjutan (PKB) (Buku 5). Jakarta: Pusat Pengembangan Profesi Pendidik Badan Pengembangan Sumber Daya Manusia Pendidikan dan Penjaminan Mutu Pendidikan Kemendiknas.

Lyesmaya, D., dkk. (2016). Analisis karya ilmiah guru dalam program PKB. Sukabumi: LPPM-UMMI-Laporan Penelitian.

Peraturan Pemerintah RI Nomor 74 Tahun 2008 Tentang Guru (Lembaran Negera RI Tahun 2008 Nomor 194). 
Undang-Undang No. 20 Tahun 2003 Tentang Sistem Pendidikan Nasional. Bandung: Cita Umbara.

\section{Ucapan Terimakasih}

Ucapan terimakasih disampaikan kepada dosen dan mahasiswa prodi PGSD-FKIP-UMMI dan UNISMA yang telah berkontribusi langsung sebagai fasilitator dalam kegiatan dan kepada LPPM UMMI dan UNISMA yang telah mengizinkan kami dalam melakukan pengabdian ini. Terimakasih disampaikan juga kepada Kepala BKD Sukabumi, Kepala UPT Kota Sukabumi yang telah memberikan fasilitas dan memberikan informasi sehingga kegiatan ini berjalan sesuai dengan yang direncanakan. Selain itu, Kegiatan pengabdian kepada masyarakat ini terwujud berkat kerjasama dengan Dinas Pendidikan dan Kebudayaan Kota Sukabumi khususnya Kasubag.Kepegawaian terutama pada bina program yang telah memfasilitasi program Pengabdian kepada Masyarakat ini, sehingga program ini berjalan lancar. Untuk itu, ucapan terimakasih, apresiasi, dan penghargaan yang setinggi tingginya kepada Dinas P\&K Kota Sukabumi kami sampaikan atas perhatian dan kepedulian terhadap peningkatan profesionalisme guru SD di Kota Sukabumi. 